\title{
Coordinated changes of sea ice over the Beaufort and Chukchi seas: regional and seasonal perspectives
}

\author{
Xiangdong Zhang, Moto Ikeda \& John E. Walsh
}

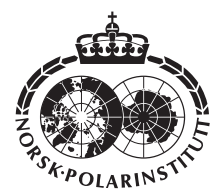

One outstanding feature of the recent Arctic climate is the contrast of the changes of sea ice concentration and thickness between the Beaufort Sea and the Chukchi Sea. Since the Arctic Oscillation (AO) plays a critical role in driving Arctic sea ice changes and the Beaufort and Chukchi seas have been hypothesized as a region in which sea ice anomalies originate, we employed a coupled sea ice-ocean model and carried out simulations forced by the AO signal to examine sea ice changes in these regions, focusing on seasonality. With the AO phase transition from negative to positive, anticyclonic windstress weakens broadly in both winter and summer; however, the surface air temperature response shows remarkable seasonal dependence. Positive temperature anomalies spread over the entire domain in winter, while negative anomalies occur in the shelf seas in summer, although positive anomalies remain in the deep-water portion. The simulated sea ice concentration resembles the observed concentration. The strong seasonality of sea ice concentration changes suggests that accumulation of sea ice concentration in the Beaufort Sea and reduction in the Chukchi Sea are mainly produced in summer. Changes of ice thickness are robust through the seasonal cycle. Generally, sea ice dynamics play a critical role in creating the anomalous sea ice pattern and sea ice thermodynamics partially compensate the dynamically-driven changes. However, considerable seasonal differences occur.

X. Zhang, M. Ikeda \& J. E. Walsh, International Arctic Research Center, University of Alaska Fairbanks, Fairbanks, AK 99775, USA, xdz@iarc.uaf.edu; M. Ikeda, Hokkaido University, Sapporo 060-0810, Japan.

Dramatic changes have been recently detected in the Arctic climate. The change in the atmosphere is characterized by the weakening of the Beaufort High (Walsh et al. 1996) as part of the pronounced fluctuation of the Arctic or the North Atlantic Oscillation (AO, NAO) (Thompson \& Wallace 1998; Hurrell 1995). Analyses of SMMR and SSM/I data during the period of 1978-1998 have shown a reduction of about $3 \%$ per decade in total sea ice area (Johannessen et al. 1999; Parkinson et al. 1999). Rothrock et al. (1999) reported a mean decrease of $1.3 \mathrm{~m}$ in sea ice thickness (SIT) at the end of the melt season in the deep-water portion between 1958-1976 and the 1990s, which could be due to an atmospherically induced shift in the relatively thick central Arctic ice toward northern Canada (Holloway \& Sou 2001).

An outstanding feature of these changes is the contrast of sea ice variations between the Beaufort Sea and the Chukchi Sea. Sea ice concentration (SIC) has decreased tremendously in the Chukchi Sea but it has increased remarkably in the Beaufort Sea, as shown in the SIC and sea surface temperature data set HadISST1.1 (Parker et al. 1995; X. Zhang et al. 2003). Several modelling studies (e.g. J. Zhang et al. 2000; X. Zhang et al. 2003) have addressed variability of annual mean SIC and SIT on the Arctic basinscale. Mysak et al. (1990) hypothesized that the Beaufort and Chukchi seas are the origin of sea 


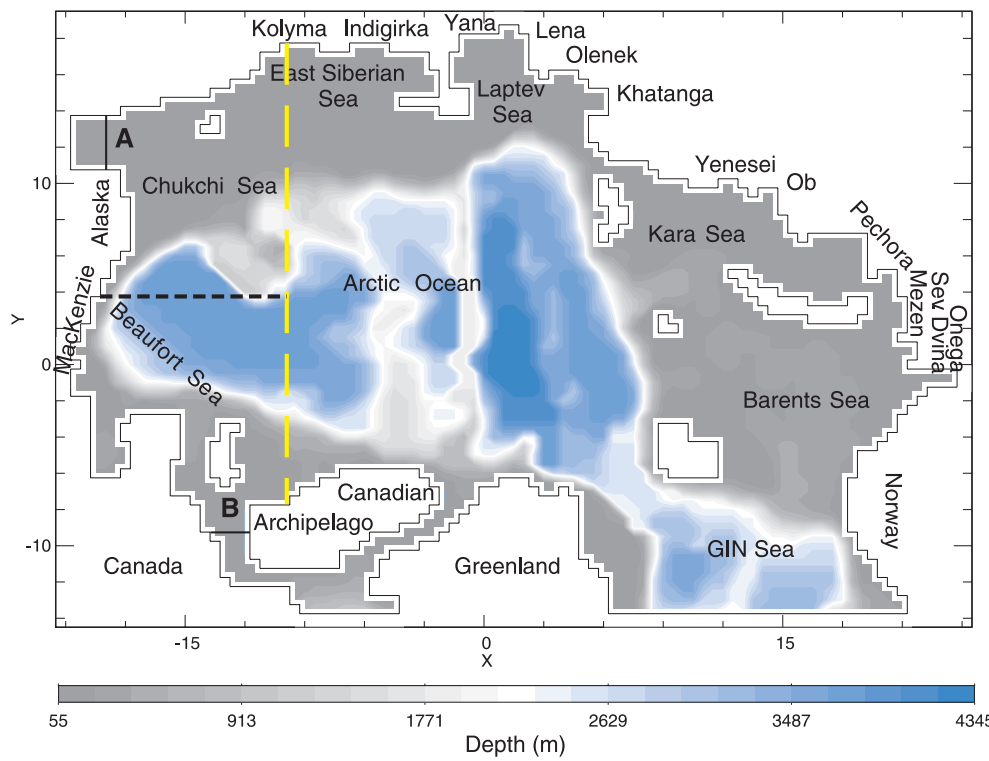

Fig. 1. Bathymetry of the model domain. The total area of the Beaufort and Chukchi seas is bounded by the vertical yellow dashed line. The horizontal black dashed line separates the Beaufort Sea and the Chukchi Sea. A and $B$ are vertical sections in Bering and Barrow straits for diagnosis. $\mathrm{X}$ and $\mathrm{Y}$ denote the grid points of model domain. The grid spacing is $55 \mathrm{~km}$.

ice anomalies travelling to the Greenland Sea. However, the changes of SIC and SIT over the Beaufort and Chukchi seas are apparently exaggerated (relative to observations) in J. Zhang et al. (2000). Arfeuille et al. (2000) found indications of movement of sea ice volume anomalies in the Arctic Ocean in their modelling but they did not find exchanges between the Beaufort Sea and the Chukchi Sea. In this paper, we focus on the Beaufort and Chukchi seas by evaluating sea ice changes and their seasonality and exploring underlying dynamic and thermodynamic mechanisms in the context of the AO.

\section{Model and forcing data}

The Arctic coupled ocean-sea ice model used here was developed for climate studies by Zhang \& Zhang (2001). The ocean component is based on GFDL MOM2.0 (Pacanowski 1995) and includes the flux-corrected-transport (FCT) algorithm (Gerdes et al. 1991). The sea ice model is based on dynamics presented by Hibler (1979) and thermodynamics by Parkinson \& Washington (1979), with modifications of snow treatments in accordance with Fichefet \& Maqueda (1997).

Zhang \& Zhang (2001) developed a synchronous coupling scheme between ocean and sea ice to help heat and salt conservation. A simple parameterization of brine rejection and more sophisticated parameterizations of heat and freshwater fluxes are implemented, including stability-dependent sensible and latent heat fluxes and Arctic-specific parameterizations of downwelling shortwave and longwave radiation (Key et al. 1996). Penetration of shortwave radiation through bare sea ice is included. Freshwater fluxes result from sea ice growth/melt, snowmelt, precipitation and river run-off.

The model domain extends from Norway and Fram Strait to the Bering Strait with a horizontal resolution of $55 \mathrm{~km}$ by $55 \mathrm{~km}$. Oceanic inflows at the open boundaries in the Bering Strait, Baffin Bay and the Greenland-Iceland-Norwegian (GIN) seas are specified as $0.85 \mathrm{~Sv},-1.70 \mathrm{~Sv}$ and $0.85 \mathrm{~Sv}$, respectively, allowing water exchanges between the Arctic and the North Pacific and the North Atlantic. In this study, we focus on the Beaufort and Chukchi seas (Fig. 1).

The forcing data, constructed from NCEP/ NCAR reanalysis from 1958 to 1998 (Kalnay et al. 1996), includes surface windstress, $2 \mathrm{~m}$ air temperature, $2 \mathrm{~m}$ specific humidity and surface pressure. Climatological precipitation and river run-off are taken from observations (Legates \& Willmott 1990; Becker 1995; data also supplied by the National Snow and Ice Data Center). To isolate sea ice changes driven by the AO mode, forcing anomalies regressed onto the monthly $\mathrm{AO}$ index are added to and subtracted from the climatic monthly mean from 1958 through 1998, 

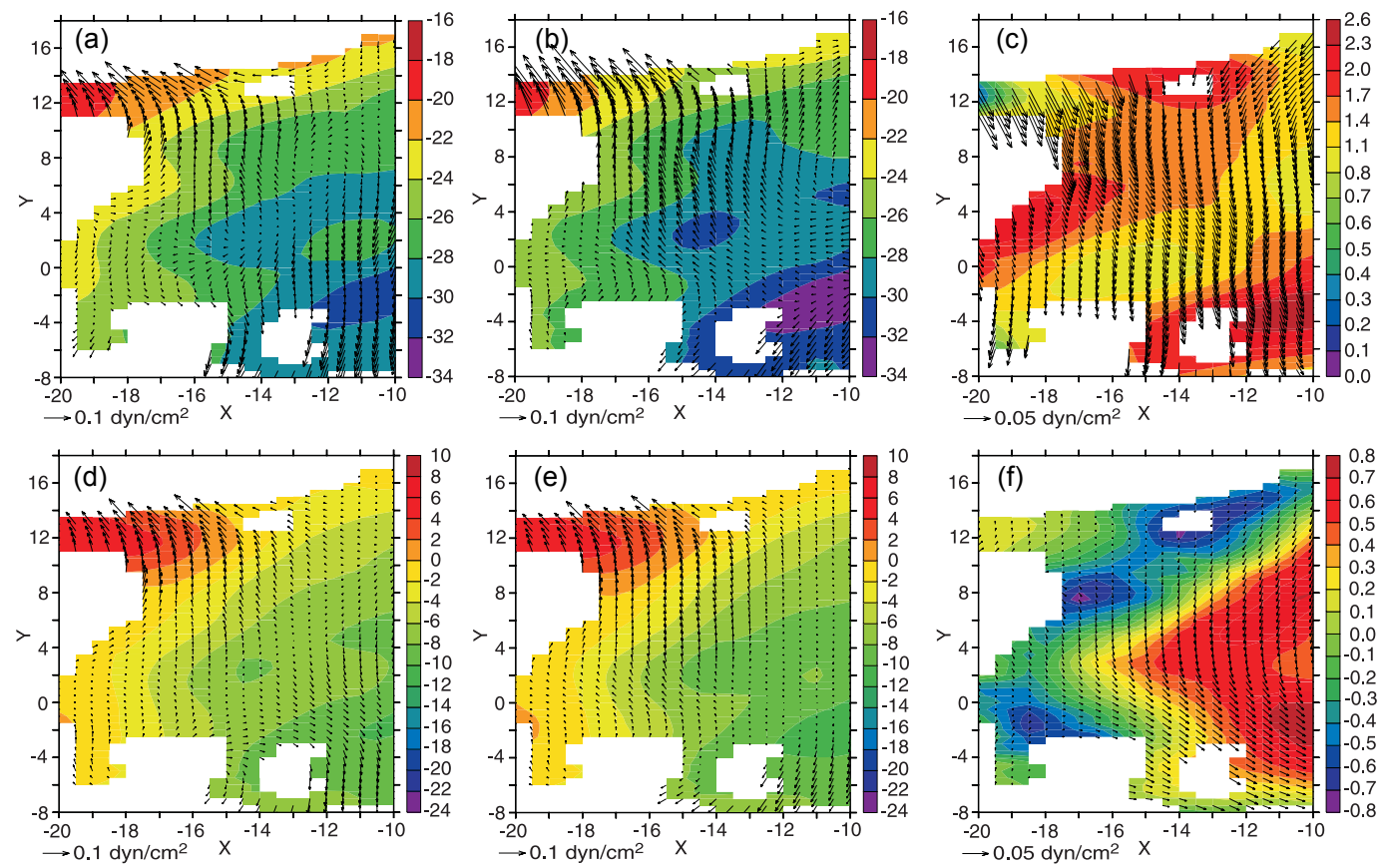

Fig. 2. Winter $2 \mathrm{~m}$ air temperature and windstress in the (a) positive and (b) negative phases of the AO, and (c) their difference. Summer $2 \mathrm{~m}$ air temperature and windstress in the (d) positive, (e) negative phase of the AO, and (f) their difference. The unit of air temperature scaled by the colour bars is ${ }^{\circ} \mathrm{C}$.

respectively, to produce the monthly data corresponding to the positive and negative phases of the AO (X. Zhang et al. 2003).

The model was first integrated without initial sea ice for 120 years forced by 41 -year mean climate monthly data described above from initial temperature and salinity from Levitus (1982). After about 100 years, an approximate equilibrium state was reached by the sea ice and upper ocean properties (Zhang \& Zhang 2001). Two additional 10-year simulations were then carried out with the forcing data corresponding to the positive and negative phase of the $\mathrm{AO}$, respectively. Output from the last year of each simulation has been analysed. Because the maximum sea ice extent occurs in March and the minimum in September, we choose these two months to represent winter and summer, respectively.

\section{Results}

\section{Changes of atmospheric forcing}

The winter and summer $2 \mathrm{~m}$ air temperature and windstress in the positive and negative phases of the $\mathrm{AO}$, and their differences, are shown in Fig. 2. During winter, cold air spreads over the entire domain. The average surface air temperature is around $-20^{\circ} \mathrm{C}$ to $-30^{\circ} \mathrm{C}$ over most of the Beaufort and the Chukchi seas in both phases. During summer, surface air temperature increases to above freezing point over the Bering Strait, while temperatures vary between $0{ }^{\circ} \mathrm{C}$ and $-10^{\circ} \mathrm{C}$ over the Beaufort and Chukchi seas. The prevailing windstress is from the Beaufort toward the Chukchi Sea in the negative phases of the AO from winter through summer; this prevailing windstress is actually a part of the Beaufort High. However, a portion of windstress directed from the Chukchi Plateau towards the northern American coast occurs in the positive phase in winter. In particular, an anticyclonic cell appears over the Chukchi Plateau, reflecting the contraction of the Beaufort High.

The changes of surface air temperature and windstress are shown in Fig. $2 c$ and f. From the negative to the positive phase of the $\mathrm{AO}$, changes of surface air temperature show considerable seasonality. The temperature increases over the entire domain in winter, with the largest increase 

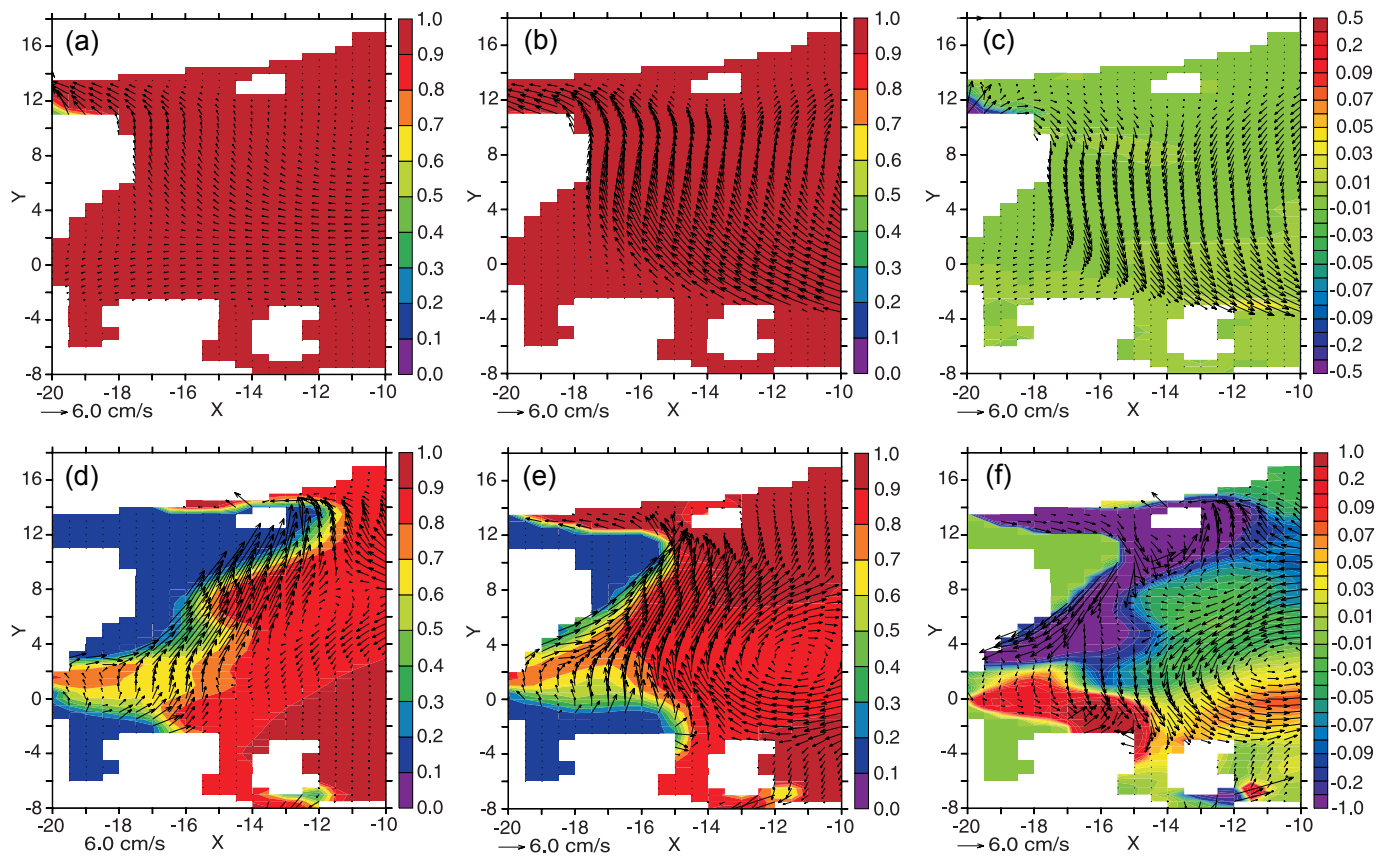

Fig. 3. Winter sea ice concentration and velocity in the (a) positive, (b) negative phase of the AO, and (c) their difference. Summer sea ice concentration and velocity in the (d) positive, (e) negative phase of the AO, and (f) their difference. The unit of sea ice concentration scaled by the colour bars is $\times 100 \%$.

occurring over the areas from the Chukchi Sea to the Alaska shelf seas and near the Canadian Archipelago, while it decreases in the shelf seas in summer, although it remains an increase in the deep-water portion. In both seasons, the anomalous windstress in the positive $\mathrm{AO}$ phase is directed from the Chukchi toward the Beaufort Sea, opposite to the prevailing windstress in both phases of the AO. This implies that windstress from the Beaufort Sea to the Chukchi Sea weakens in the positive phase compared with the negative phase.

\section{Changes of sea ice}

Sea ice covers almost the entire domain from the Chukchi to the Beaufort Sea during winter in both the positive and negative phases (Fig. $3 \mathrm{a}, \mathrm{b})$. However, sea ice concentration decreases noticeably during summer and open water occurs in part of the Chukchi and Beaufort seas (Fig. $3 \mathrm{~d}$, e). Sea ice covers the deep-water portion and extends to the Alaska coast. Sea ice moves broadly from the Beaufort toward the Chukchi Sea during both seasons in the both phases of the $\mathrm{AO}$, which is consistent with windstress. The sea- ice motion from the Beaufort toward the Chukchi Sea is a part of the Beaufort Gyre. Specifically, an anticyclonic gyre is well organized in summer.

The observed and simulated annual mean SIC shows an increase in the Beaufort Sea and a decrease in the Chukchi Sea (X. Zhang et al. 2003) during the positive AO phase. Nevertheless, with the phase transition of the AO mode from the negative to positive, SIC shows considerable changes in summer but little in winter (Fig. $3 \mathrm{c}, \mathrm{f})$, suggesting a strong seasonal preference. In summer, a large decrease of SIC occurs in the Chukchi Sea during the positive phase; conversely, a large increase of SIC appears in the Beaufort Sea. In winter, SIC does not change markedly; there is only a minor increase along the Canadian coast (Fig. 3c). This is because surface air temperature still drops below freezing point to result in sea ice growth, although it is much increased in the positive phase of the AO. The results imply that the anomalous SIC pattern is mainly produced in summer.

Anomalous sea ice motion from the Chukchi Sea toward the Beaufort Sea occurs when the AO is positive, consistent with changes of windstress. In particular, the well organized Beaufort Gyre 

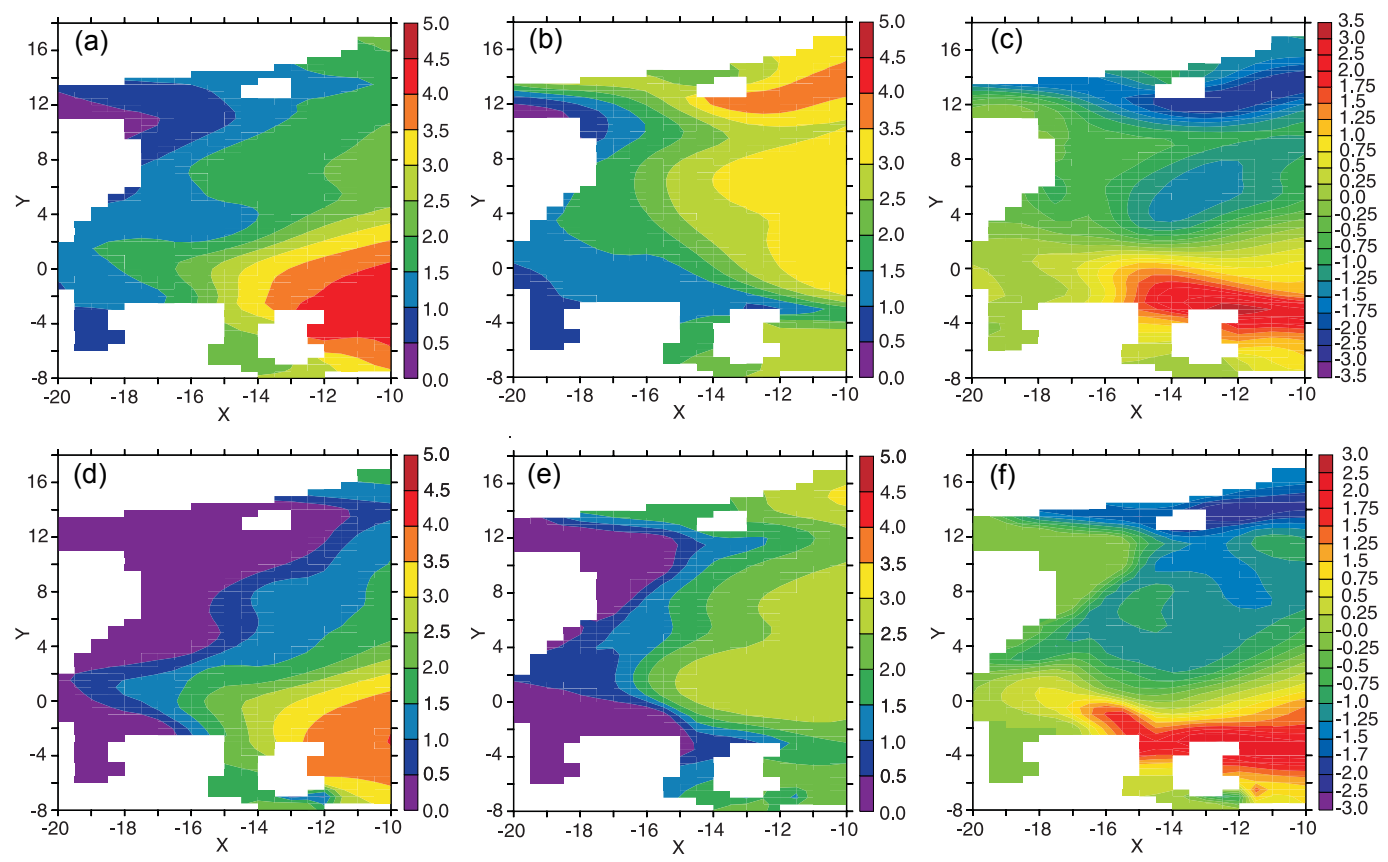

Fig. 4. Winter sea ice thickness in the (a) positive, (b) negative phase of the AO, and (c) their difference. Summer sea ice thickness in the (d) positive, (e) negative phase of the AO, and (f) their difference. The unit of sea ice thickness scaled by the colour bars is metres.

in the negative phase in summer (Fig. 3e) is substantially weakened and deformed in the positive phase (Fig. 3d). A resulting anomalous cyclonic circulation occurs.

The SIT, plotted in Fig. 4, shows considerable and robust changes with the phase shift of the $\mathrm{AO}$ from the negative to the positive in both winter and summer. SIT represents sea ice volume per square unit and is an effective integrator of sea ice changes. As shown in Fig. 4c-f, SIT decreases substantially in the Chukchi Sea when the AO is positive. By contrast, SIT increases substantially in the Beaufort Sea. The maximum increase of SIT reaches over $2.0 \mathrm{~m}$.

\section{Thermodynamics and dynamics of sea ice changes}

Associated with the phase transition of the AO mode are changes of heat and momentum fluxes, which are reflected in the surface air temperature and windstress changes shown in Fig. 2. These changes affect both the sea ice thermodynamics and dynamics. Because dynamic and thermodynamic processes are inherently coupled in sea ice, sea ice redistribution is determined by inter- actions of dynamic and thermodynamic processes. In the positive phase of the $\mathrm{AO}$, the generally warmer air will intuitively tend to reduce sea ice area and volume. However, sea ice transport, convergence and divergence resulting from dynamics modify and even dominate the thermodynamic consequence for interannual sea ice fluctuation (Walsh et al. 1985).

To elucidate the thermodynamic and dynamic roles in sea ice changes over the Chukchi and Beaufort seas, we present diagnostic results of sea ice growth/melt and net lateral transports in Fig. 5. The sea ice growth/melt is governed by thermodynamic processes, not including changes of volume resulting directly from deformation, although deformation ultimately affects the growth/melt rates. The transport is determined by the sea ice volume and velocity across boundaries.

Sea ice growth occurs from fall to spring and sea ice melt occurs during summer over the Beaufort and Chukchi seas in both phases of the $\mathrm{AO}$ (Fig. 5a, b). However, changes of sea ice growth/ melt from the negative to the positive phase of the AO are of opposite sign in the Beaufort and the Chukchi Sea. During the positive AO, sea ice 
(a)

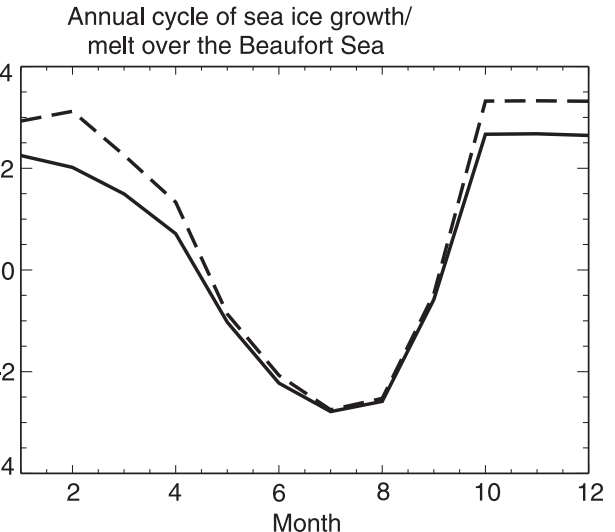

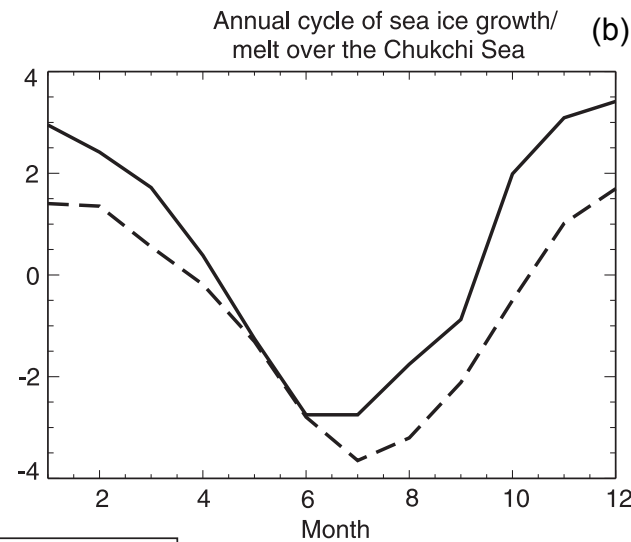

Positive phase

Negative phase Annual cycle of net sea ice lateral Annual cycle of net sea ice lateral
transport in the Chuckchi Sea

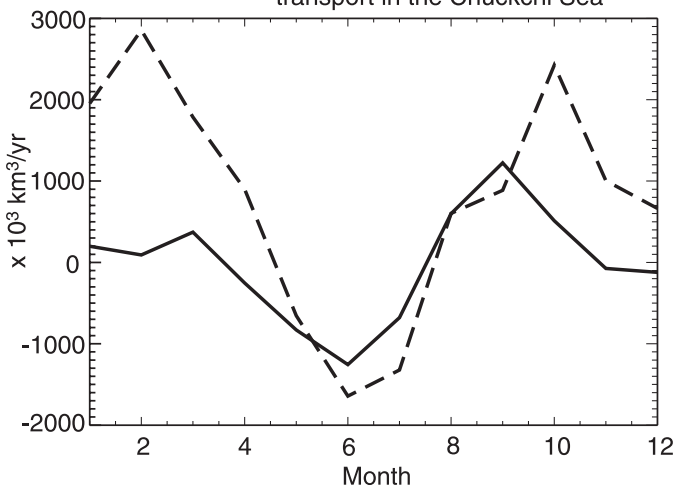

Fig. 5. Annual cycle of sea ice growth/melt rate in (a) the Beaufort Sea and (b) the Chukchi Sea. Annual cycle of net sea ice transport in (c) the Beaufort Sea and (d) the Chukchi Sea.

growth is considerably weakened over the Beaufort Sea while it is intensified over the Chukchi Sea from fall to spring. A small increase of sea ice melt occurs in the Beaufort Sea but a tremendous decrease of sea ice melt occurs in the Chukchi Sea during summer in the positive phase. Part of this decrease may be a consequence of there being less sea ice to melt in areas of thinner ice and of decreasing air temperature associated with the AO mode over the shelf seas. Accordingly, thermodynamics brings about less sea ice production over the Beaufort Sea but more production over the Chukchi Sea in the positive phase of the AO.

These thermodynamic responses seem contrary to the changes of SIC and SIT shown in Fig. 3, so other factors are evidently responsible for the sea ice redistribution. The sea ice transports into and out of the Beaufort and Chukchi seas provide another perspective. Sea ice transport from the Beaufort to the Chukchi Sea represents a sink of sea ice for the former and a source for the latter. In addition, the Canada Basin is a source of sea ice to the Beaufort Sea while the Chukchi Sea loses sea ice to the East Siberian Sea. Exports of sea ice through the Barrow and Bering straits usually result in sea ice losses in both the Beaufort and the Chukchi Sea. The resultant net sea ice transports in the Beaufort Sea and the Chukchi Sea are plotted in Fig. $5 \mathrm{c}$ and d. The amplitude of the seasonal cycle of net transport is suppressed in the positive phase of the AO. Nevertheless, the changes with the AO phase transition are considerable and their seasonality is significant. The Beaufort Sea gains but the Chukchi Sea loses sea ice volume from fall to spring, while the Beaufort Sea loses but the Chukchi Sea gains sea ice volume in summer with the AO phase from nega- 
tive to positive. In the annual mean, there is a net gain of sea ice in the Beaufort Sea, around 462.9 $\mathrm{km}^{3} / \mathrm{yr}$ but a net loss of sea ice in the Chukchi Sea, around $-910.8 \mathrm{~km}^{3} / \mathrm{yr}$, in the positive phase of the AO.

A detailed diagnosis shows that the sea ice transport between the Beaufort and the Chukchi Sea plays a dominant role in the net gain or net loss of sea ice volume in these two regions. Sea ice transport from the Beaufort to the Chukchi Sea drops dramatically, by about $87 \%$, in the positive phase of the AO compared with the negative phase. Although sea ice input from the Canada Basin decreases, sea ice export through the Barrow Strait increases and sea ice losses by the transport toward the East Siberian Sea and through the Bering Strait decrease, changes of these transports still cannot offset the changes of the transport between the Beaufort Sea and the Chukchi Sea.

Consequently, the interaction of sea ice thermodynamics and dynamics critically determines sea ice production, loss and re-distribution. Dynamics play a dominant role in creating the anomalous sea ice pattern. Thermodynamics partly serve as a compensating factor. Both the dynamics and the thermodynamics exhibit obvious seasonality in contributing to sea ice changes.

\section{Concluding remarks}

The Beaufort and Chukchi seas are hypothesized as an origin of sea ice anomalies (Mysak et al. 1990). A noticeable contrast of the changes of annual mean SIC has been manifested in this region in observations (X. Zhang et al. 2003). However, the sea ice compacting off the Alaskan and Canadian coasts in the Beaufort Sea is exaggerated in the recent modelling by J. Zhang et al. (2000) and the sea ice anomaly transport from the Beaufort to the Chukchi Sea was not found by Arfeuille et al. (2000). We employed our own coupled ocean-sea ice model and carried out simulations forced by the AO signal to explore the formation of sea ice anomalies and their underlying physical mechanisms in this region. Seasonality of sea ice changes in the Beaufort and Chukchi seas forced by the AO is the focus of this paper.

With the transition of the $\mathrm{AO}$ from negative to positive phase, anticyclonic windstress weakens, reflecting the degeneration of the Beaufort High. Considerable seasonality occurs for the surface air temperature. It increases over the entire domain of the Beaufort and Chukchi seas in winter but it decreases over the shelf seas in summer in spite of the fact that the positive air temperature anomalies remains in the portion of deep water.

The AO signal coordinates the SIC and SIT changes in the Beaufort and Chukchi seas. Changes of SIC show noticeable seasonal variations with minimum changes in winter because the heat budget is always negative, enabling ocean surface temperature to drop to the freezing point. SIC increases markedly in the Beaufort Sea and decreases in the Chukchi Sea in summer in the positive AO. This implies that the observed annual SIC changes from 1979-1988 to 19891998 in HadISST 1.1 are mainly produced in summer. Changes of sea ice thickness are robust through the whole year.

Sea ice dynamics plays a critical role in forming the anomalous sea ice pattern. The changed sea ice transports during the positive AO phase result in a net inflow into the Beaufort Sea and a net outflow out of the Chukchi Sea from fall to spring, which dominate the net transports of opposite sign in summer. Thermodynamic consequences only partially offset the dynamics. From the negative to the positive phase of the AO relative to the negative phase, sea ice growth intensifies in the Chukchi Sea and weakens in the Beaufort Sea from autumn through spring; sea ice melt decreases in the Chukchi Sea but increases in the Beaufort Sea during summer, reflecting a negative feedback on sea ice variability significantly different from J. Zhang et al.'s (2000) positive feedback on their east/west Arctic sea ice changes. A notable substantiation of the conclusion that dynamics, not thermodynamics, drive the sea ice variations is that the positive $\mathrm{AO}$ leads to reduced ice coverage in the Chukchi Sea (Fig. 3f) despite the fact that the summer air temperatures in the forcing from the NCEP reanalysis were actually colder for the positive phase of the AO (Fig. 2f).

This study has provided a quantitative demonstration of the compensating nature of the dynamic and thermodynamic responses to the $\mathrm{AO}$ in the Beaufort and Chukchi seas in numerical model simulations, with particular attention to seasonality and to the relative roles of dynamics and thermodynamics. With regard to the latter, our results agree with Rigor et al.'s (2002) recent observational analysis, which suggested that the 
dynamical response of sea ice to the wintertime AO provides a "footprint" that persists through the following spring and summer. It is hoped that the results of this study will stimulate further measurements and analyses to confirm the findings.

Acknowledgements-We thank the Climate Diagnostics Center/NOAA for providing the NCEP/NCAR reanalysis data and the National Snow and Ice Data Center for providing the Russian river run-off data. The Arctic Region Supercomputing Center supplied some computer resources. We are grateful to the reviewers for valuable comments. X. Zhang and M. Ikeda are funded by the National Space Development Agency of Japan and the Japanese Marine Science and Technology Center through the Frontier Research System for Global Change/International Arctic Research Center, University of Alaska Fairbanks. J. E. Walsh is funded by the National Science Foundation.

\section{References}

Arfeuille, A., Mysak, L. A. \& Tremblay, L.-B. 2000: Simulation of the interannual variability of the wind-driven Arctic sea-ice cover during 1958-1998. Clim. Dyn. 16, 107-121.

Becker, P. 1995: The effect of Arctic hydrological cycles on Arctic Ocean circulation. PhD thesis, Old Dominion University. Norfolk, VA.

Fichefet, T. \& Maqueda, M. A. M. 1997: Sensitivity of a global sea ice model to the treatment of ice thermodynamics and dynamics. J. Geophys. Res. 102(C6), 12609-12 646.

Gerdes, R., Koberle, C. \& Willebrand, J. 1991: The influence of numerical advection schemes on the results of ocean general circulation models. Clim. Dyn. 5, 211-226.

Hibler, W. D. III 1979: A dynamic thermodynamic sea ice model. J. Phys. Oceanogr. 9, 815-846.

Holloway, G. \& Sou, T. 2001: Is Arctic sea ice thinning rapidly? Ice Clim. News 1, 2.

Hurrell, J. W. 1995: Decadal trends in the North Atlantic oscillation: regional temperature and precipitation. Science 269, 676-679.

Johannessen, O. M., Shalina, E. V. \& Miles, M. W. 1999: Satellite evidence for an Arctic sea ice cover in transformation. Nature 286, 1937-1939.

Kalnay, E., Kanamitsu, M., Kistler, R., Collins, W., Deaven,
D., Gandin, L., Iredell, M., Saha, S., White, G., Woollen, J., Zhu, Y., Leetmaa, A., Reynolds, R., Chelliah, M., Ebisuzaki, W., Higgins, W., Janowiak, J., Mo, K. C., Ropelewski, C., Wang, J., Jenne, R. \& Joseph, D. 1996: The NCEP/ NCAR 40-year reanalysis project. Bull. Am. Meteorol. Soc. 77, 437-471.

Key, J. R., Silcox, R. A. \& Stone, R. S. 1996: Evaluation of surface radiative flux parameterizations for use in sea ice models. J. Geophys. Res. 101(C2), 3839-3849.

Legates, D. R. \& Willmott, C. J. 1990: Mean seasonal and spatial variability in gauge-corrected, global precipitation. Int. J. Climatol. 10, 111-127.

Levitus, S. 1982: Climatological atlas of the world ocean. NOAA Prof. Pap. 13. Washington, D. C.

Mysak, L. A., Manak, D. K. \& Marsden, R. F. 1990: Sea-ice anomalies observed in the Greenland and Laborador seas during 1901-1984 and their relations to an interdecadal Arctic climate cycle. Clim. Dyn. 5, 111-113.

Parker, D. E., Folland, C. K., Bevan, A., Ward, M. N., Jackson, M. \& Maskell, K. 1995: Marine surface data for analysis of climate fluctuations on interannual to century timescales. In D. G. Martinson et al. (eds.): Natural climate variability on decadal to century timescales. Pp. 241-250. Washington, D. C.: National Academy Press.

Parkinson, C. L., Cavalieri, D. J., Gloersen, P., Zwally, H. J. \& Comiso, J. C. 1999: Arctic sea ice extents, areas, and trends, 1978-1996. J. Geophys. Res. 104(C9), 20837-20856.

Parkinson, C. L. \& Washington, W. M. 1979: Large-scale numerical-model of sea ice. J. Geophys. Res. 84(NC1), 311-337.

Rigor, I. G., Wallace, J. M. \& Colony, R. L. 2002: Response of sea ice to the Arctic Oscillation. J. Clim. 15, 2648-2663.

Rothrock, D. A., Yu, Y. \& Maykut, G. A. 1999: Thinning of the Arctic sea-ice cover. Geophys. Res. Lett. 26, 34693472.

Thompson, D. W. \& Wallace, J. M. 1998: The Arctic Oscillation signature in the wintertime geopotential height and temperature fields. Geophys. Res. Lett. 25, 1297-1300.

Walsh, J. E., Chapman, W. L. \& Shy, T. L. 1996: Recent decrease of sea level pressure in the central Arctic. J. Clim. 9, 480-486.

Walsh, J. E., Hibler, W. D. III \& Ross, B. 1985: Numericalsimulation of Northern Hemisphere sea ice variability. $J$. Geophys. Res. 90(NC3), 4847-4865.

Zhang, J., Rothrock, D. \& Steele, M. 2000: Recent changes in the Arctic sea ice: interplay between ice dynamics and thermodynamics. J. Clim. 13, 3099-3114.

Zhang, X., Ikeda, M. \& Walsh, J. E. 2003: Arctic sea-ice and freshwater changes driven by the atmospheric leading mode in a coupled sea-ice/ocean model. J. Clim. 16, 2159-2177.

Zhang, X. \& Zhang, J. 2001: Heat and freshwater budgets and their pathways in the Arctic Mediterranean. J. Oceanogr. $57,207-234$ 